\title{
Correlating Conductivity with Hardness and Density in X7475 Alloys for Development of Linear Hardness Model
}

\author{
Abubakar Kazeem ${ }^{1,2}$, Amkpa Job Ajala ${ }^{3}$, Mohammed H. Rady², Nur Azam Badarulzaman²,*, \\ Wan Fahmin Faiz Wan Ali ${ }^{4}$

\begin{abstract}
${ }^{1}$ Department of Science Policy and Innovation Studies, National Centre for Technology Management (NACETEM), Nigeria ${ }^{2}$ Faculty of Mechanical and Manufacturing Engineering, Universiti Tun Hussein Onn Malaysia (UTHM), Malaysia ${ }^{3}$ Department of Foundry Engineering, Federal Polytechnic Idah, Nigeria ${ }^{4}$ Faculty of Mechanical Engineering, Universiti Teknologi Malaysia (UTM), Malaysia
\end{abstract}

Received July 30, 2019; Revised October 1, 2019; Accepted December 15, 2019

\begin{abstract}
Copyright $(2019$ by authors, all rights reserved. Authors agree that this article remains permanently open access under the terms of the Creative Commons Attribution License 4.0 International License
\end{abstract}

\begin{abstract}
Hardness (H) may not be sufficed as a property the same way density ( $\rho$ ) felt short as a measure of physical property, hence there is the need to correlate $H$ with other property (ies). The porous nature of the material, dislocations and addition of constituents to the aluminium matrix affect the conductivity $(\sigma)$ of alloys among other defects. In this article, attempt to fill the gap in recycling beverage can (RBC) for bumper beam applications was made by producing a 7xxx alloy from 3xxx alloy. About $80 \%$ of the raw materials used in this alloy were sourced from secondary means. Stir casting route was adapted. Aluminium (Al) chips, $70 \% \mathrm{Cu}-30 \% \mathrm{Al}$, Manganese (Mn) and Magnesium (Mg) were charged in that order. The relationship between $\mathrm{O}, \mathrm{H}$ and $\rho$ of the new alloy was established in the As-Cast (AC), annealed (O), natural aged (T4) and artificial aged (T6) conditions. In AC, an alloy of Al- 4.0 Zn-1.5Mg-0.35Cu-Mn recorded the peak obtainable $\mathrm{O}$ and $\mathrm{H}$ of $3.7 \times 10^{7} \mathrm{~m} / \mathrm{S}$ and $113.06 \mathrm{Hv}$ with a $\rho$ of $2.7464 \mathrm{~g} / \mathrm{cm}^{-3}$. The same alloy recorded peak $\mathrm{O}$ and $\mathrm{H}$ in the $\mathrm{O}$ condition of $3.7 \times 10^{7} \mathrm{~m} / \mathrm{S}$ and $102.6 \mathrm{Hv}$, whereas the $\rho$ was $2.752 \mathrm{~g} / \mathrm{cm}^{-3}$. The T4 heat treatment (HT) deviated when the peak $\mathrm{O}$ was $3.7 \times 10^{7} \mathrm{~m} / \mathrm{S}, \mathrm{H}$ and $\rho$ were $58.94 \mathrm{Hv}$ and $2.7551 \mathrm{~g} / \mathrm{cm}^{-3}$ respectively. T6 conditioned alloys delivered peak $\mathrm{O}$ of $3.7 \times 10^{7} \mathrm{~m} / \mathrm{S}$ in an alloy of Al- 4.0 $\mathrm{Zn}-1.5 \mathrm{Mg}-0.35 \mathrm{Cu}-\mathrm{Mn}$ with a $\rho$ of $2.7853 \mathrm{~g} / \mathrm{cm}^{-3}$ and 60.26 Hv. HT and formation of precipitates were detrimental to $\bar{O}$ and beneficial to $\mathrm{H}$. Curve fittings were obtained and used in developing linear models for the relationship between $\mathrm{H}$ and $\sigma$ within respective conditions unique to the experimental alloys.
\end{abstract}

Keywords Conductivity, Hardness-Conductivity Linear Model, X7475 Al-Alloy, Recycled-Beverage-Can

\section{Introduction}

The roles of precipitate and dislocations in physical and mechanical properties of $\mathrm{Al}-\mathrm{Zn}-\mathrm{Mg}-\mathrm{Cu}$ alloys were well known in the literature [1, 3]. Phases were formed from the addition of metallic alloying constituents. On the other hand, these additions were more detrimental to electrical $O$ in the solid solution conditions than in the T4 and T6 out of solution conditions, although aluminium is known for high $\widetilde{\sigma}[1]$. The relevance of the hardening phases formed by additional constituents is linked to $H, \rho$ and other mechanical properties. $\widetilde{O}$ predicts the phase transformation and the values may be indirect indication of the type, size and amount of precipitate formed [2]. This property is equally affected by the nature of precipitates [3].

The 3xxx is a class of Al-Mg-Mn alloy, while the $7 \mathrm{xxx}$ is an Al-Zn-Mg-Cu alloy [4]. An experimental alloy of the X7475 becomes imperative to improve on the mechanical properties of the RBC and use such for engineering applications like in the automobile or aerospace industries. An earlier publication Kazeem et al [5] recommended the need to correlate $\mathrm{H}$ with electrical $\mathrm{O}$, following the opinion expressed in the work of Salazar-Guapuriche et al.[3] , hence his paper was targeted at filling this gap. The curiosity to explore used beverage can for automobile applications and beyond motivating the choice of RBCs as raw materials in the current study.

The objective of this work therefore was to correlate the relationship between electrical $\mathrm{O}, \mathrm{H}$ and $\rho$ of the novel $\mathrm{X}$ 7475 experimental alloy produced and exposed to different 
HT conditions. In addition, the properties obtained were used in developing a statistical model to predict the $\mathrm{H}$ of these alloys at different conditions using the $\bar{\sigma}$ as a basis for the model so developed.

\section{Materials and Methods}

The raw materials used in producing the new alloy were $\mathrm{Al}, \mathrm{Zn}, \mathrm{MnO}, \mathrm{MgO}$, and $\mathrm{Cu}$. Aluminium was sourced from about $6 \mathrm{Kg}$ Al-beverage cans collected from recycle hub at the University Tun Husain Onn Malaysia (UTHM) campus and collection Centre located in Parit Raja, Johor Malaysia. $\mathrm{Zn}$ and $\mathrm{MnO}$ were sourced from spent DR 20 standard, BG/T 8897.2 - 2008 Hawk battery through physical separation techniques. The batteries were dissected using hand saw.

$\mathrm{Cu}$ was recovered from recycled standing fan with the 2-ARI 410 standard. The protective layers on the Cu-wire were removed and the wire cut to pieces to support the melting process in the Al-matrix, whereas $\mathrm{MgO}$ was as supplied.

An amalgam of $70 \% \mathrm{Cu}-30 \% \mathrm{Al}$ was produced. Ingots of $\mathrm{Zn}$ and $\mathrm{Al}$ were cast using $2 \mathrm{Kg}$ capacity induction furnace of the JT0332 model and gas fired melting furnace respectively. Sample weight \% was measured using the Mettler Toledo Model PL 303 digital weighing machine.

A modified conventional stir casting process was adopted in producing the new alloys. In alloy constituents design, the wt. \% of $\mathrm{Zn}$ varied from $5.0 \%$ - $4.0 \mathrm{wt}$. \%. Mg (1.250-1.750 wt. \%), Mn (0.050-0.100 wt. \%), and $\mathrm{Cu}$ was held at $0.35 \mathrm{wt}$. \%. It is this variation that gave birth to 9 sets of samples.

Melting was done following the variations considering initial, mid and final datum point as aforementioned, in an improvised stainless steel crucible inserted in an induction furnace of the JT0332 model. The crucible was preheated to $200{ }^{\circ} \mathrm{C}$ to eradicate moisture content and prepare it for melting. Aluminium chips, $\mathrm{Zn}, 70 \% \mathrm{Cu}-30 \% \mathrm{Al}, \mathrm{Mn}$ and $\mathrm{Mg}$ were charged sequentially while mixing was achieved using the portable hand mixer of model TAC 1803-Pentec. Hand pouring was used in feeding the preheated permanent steel mould to produce a rod of about $\varnothing 12 \mathrm{~mm}$ x $30 \mathrm{~mm}$.

A total of 36 coupons (9 samples $\mathrm{x} 4$ groups) were taken form rods and prepared for HTs. Solution treatment was done at $475{ }^{\circ} \mathrm{C}$, quenched in clean water, using Carbolite HTF 1800 box furnace per AMS 2771. Annealing, artificial and natural aging were done at 350 ${ }^{\circ} \mathrm{C}, 3$ hours holding time; $145^{\circ} \mathrm{C}, 11$ hours holding time; and $110{ }^{\circ} \mathrm{C}$, 4 hours holding time respectively.

Hardness test preparation was per modified ASTM E384-17, test was conducted using ASTM E18 route. The Shimadzu HMV-2, C227-E013, Microhardness Tester with $\mathrm{S} / \mathrm{N} 163034501261$ was engaged in the microhardness investigation. Load, duration for test and times of test were set at $490.3 \mathrm{mN}(0.05 \mathrm{Hv}), 10 \mathrm{sec}$ and 9 respectively.

A GWINSTEK LRC- 816 meter equipped with test leads of $105{ }^{\circ} \mathrm{C}, 6 \mathrm{v}$ 52386, LR 77177 CSA specifications were used in conducting 5-point probe of samples. Samples were grinded to mirror like surface before the $\delta$ test. The meter was calibrated to an accuracy of $\pm 1 \%$ ' $\Omega$ and test per ASTM E 1004 - 02 standard. The obtained resistance was converted to conductivity.

\section{Results and Discussion}

The result of $O$ in the AC alloy revealed that alloy $C$ and $\mathrm{G}$ conducted the most with $3.7 \times 10^{7} \mathrm{~m} / \mathrm{S}$ respectively. The former alloy had the maximum obtainable $\mathrm{H}$ of $113.06 \mathrm{Hv}$ and $2.7464 \mathrm{~g} / \mathrm{cm}^{-3} \rho$, whereas the latter had a load bearing capacity of $72.36 \mathrm{Hv}$ (see Figure 1 for $\mathrm{H}$ ) and $\rho$ of $2.7248 \mathrm{~g} / \mathrm{cm}^{-3}$. More on $\rho$, alloy B had the maximum $\rho$ of $2.8407 \mathrm{~g} / \mathrm{cm}^{-3}, \mathrm{O}$ of $3.5 \times 10^{7} \mathrm{~m} / \mathrm{S}$ and $\mathrm{H}$ of $87.36 \mathrm{Hv}$. 


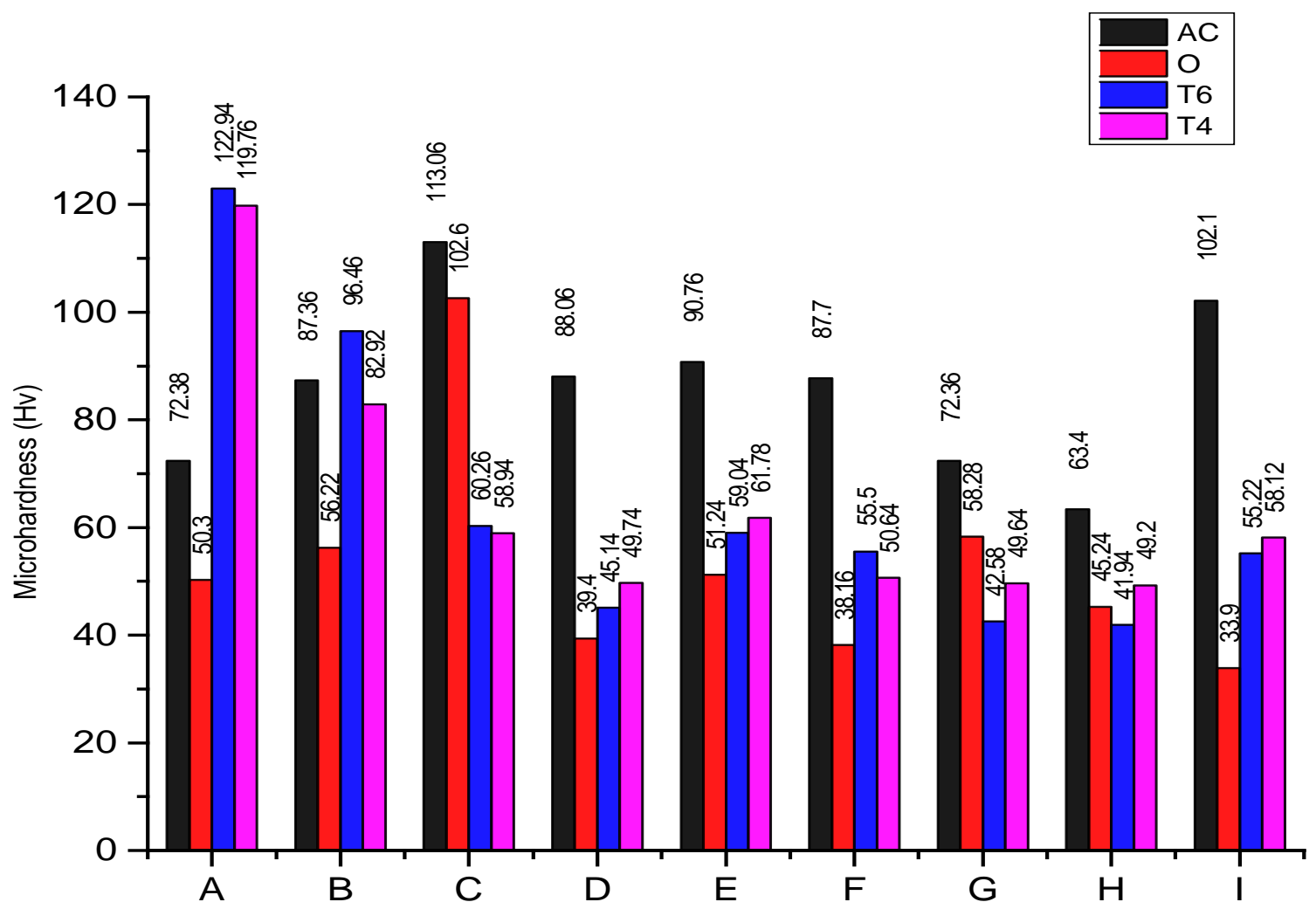

Figure 1. Microhardness of Al-Zn-Mg Alloys at Different Conditions

The implication of the physical and $\sigma$ properties displayed was linked to the non-homogenized characteristics of the AC alloy. However, the 5 wt. \% of $\mathrm{Zn}$ in $\mathrm{C}$ was responsible for the peak $\mathrm{H}$ observed in the alloy. This may not be far from the presence of impurities such as Si either [6].

Solution HT supports the formation of hardening phases like the $\mathrm{MgZn}_{2,}(\mathrm{Al}, \mathrm{Zn})_{49}(\mathrm{Mg})_{32}$ and $\mathrm{Al}_{20.4} \mathrm{Mg}_{54.9}$ $\mathrm{Zn}_{24.7}$ respectively [7]. The decline in $\mathrm{H}$ observed in the $\mathrm{O}$ condition, in contrast to AC that was as a result of the variance in $\rho$ of the alloys. Even when the phases were formed, their presence might not affect $\mathrm{H}$ hence not dispersed evenly. Sample C maintained maximum obtainable $\mathrm{H}$ of $102.60 \mathrm{Hv}$, whereas sample I recoded the least $\mathrm{H}$ of $33.90 \mathrm{Hv}$.

The correlation between $\rho$ and $\mathrm{H}$ may not be at par on the variation in the $\mathrm{H}$ and $\rho$. However, only a marginally insignificant decline was observed in $\widetilde{O}$ from the $\mathrm{O}$ conditioned alloys when compared to AC. A similar case was reported by Salazar-Guapuriche et al. [3]. The difference was due to the formation of dislocations in the form of impurities which retarded $\sigma$ in the matrix of the alloys. The increase in $\mathrm{H}$ was also linked to precipitation of the coherent phases in GP(1) in a study conducted by Feng et al [10]. Whereas, there was no significant change in $\sigma$ due to $O$ treatment condition.

The relationship between the percentage increase in $\mathrm{H}$ and residual plots for AC shown in Figure 2 (a) revealed an almost linear probability plot. Further, most of the results were clustered to the center point. Plot of residual against fitted value showed an average of the experimental values that were within the control limit of the plot. On the other hand, $25 \%$ were at the extremes of \pm 20 . Whereas, another $25 \%$ were at an interval of \pm 10 . The histogram equally showed that the relationship was a normal distribution curve. Inferentially, the fitted curves supported the model generated well and sufficed to describe the $\mathrm{H}$ behavior of this experimental alloy. The control charts revealed that the data were within controllable intervals.

The $\mathrm{O}$ condition displayed a unique property with a deviation from linearity as observed in AC samples. The data points were clustered towards the mid-point, but at different intervals from the linearity plot. The fitted value shows that about $80 \%$ of the data were well fitted at $95 \%$ confident level. There were only two extreme points at an interval of \pm 20 .

The histogram plot (Figure $2 \mathrm{~b}$ ) further established the relationship observed in the normal distribution plot. Almost $60 \%$ of the data converged at the mid-point. The versus order, a plot of the observation against residual order revealed datum 3 and 7 were far from the control line, but within a reasonable interval. The observation order revealed that alloy $\mathrm{C}$ and $\mathrm{G}$ were diverged from other points.

The analysis of artificial aging (T4) resulted in a normal probability plot (Figure $2 \mathrm{C}$ ) with about $75 \%$ converging to the center of the curve and the remaining $25 \%$ skewed 
to the positive and negative quadrant at \pm 50 . This was further established in the histogram; a major bar at the mid-point. The fitted curve revealed that the model predicted the behavior of the data fully. The convergence of data in versus first supported the versus order in the T4 condition. The interaction plot for T6 shown in Figure 2 (d) depicts similar trend.
However, the convergence of the normal probability curves to the center remains unique, an indication that the normality of the histogram is skewed between \pm 10 . Whereas two data points were between two extreme positions, the fitted curve is sufficient to represent the pattern of the data and the model so developed.
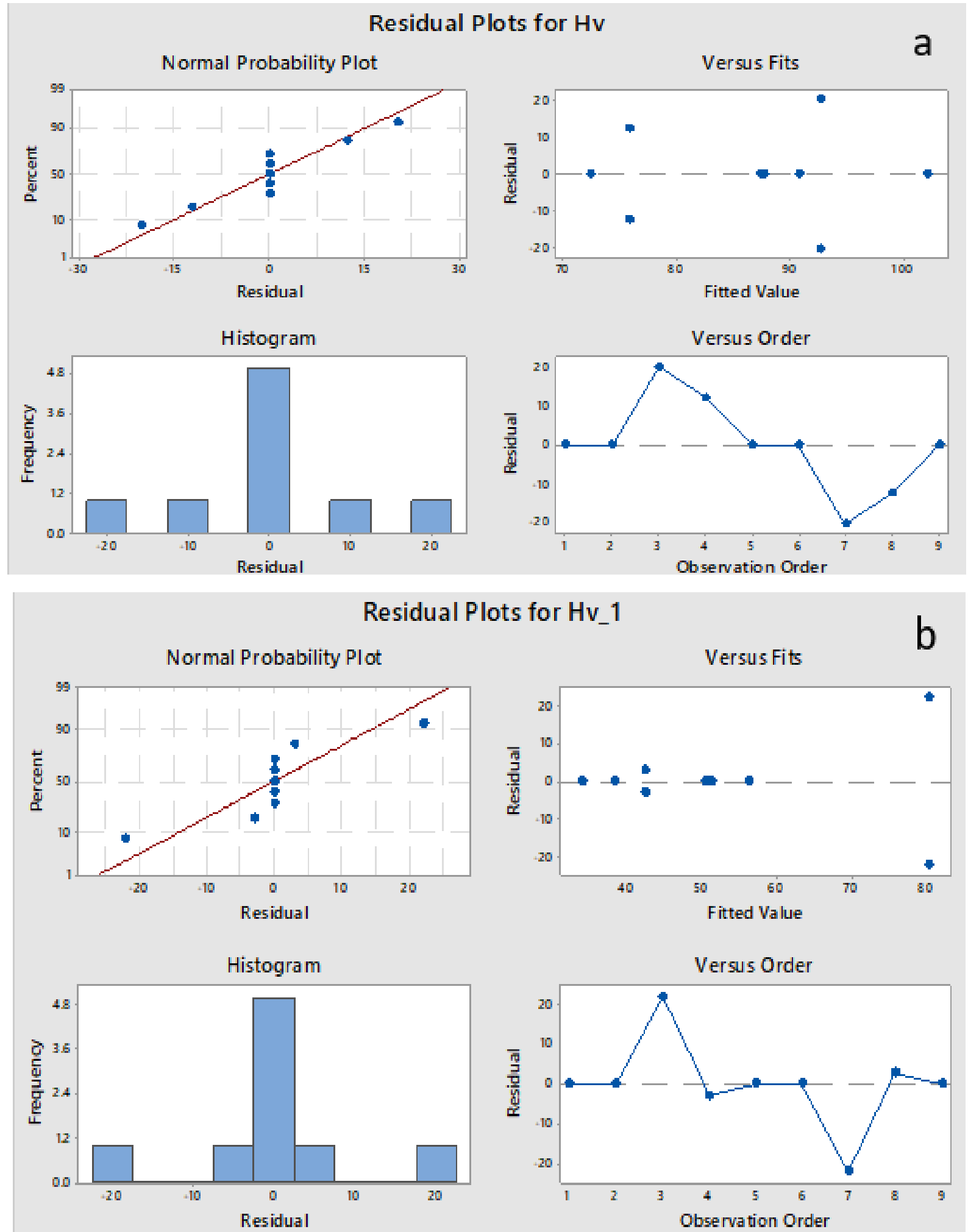

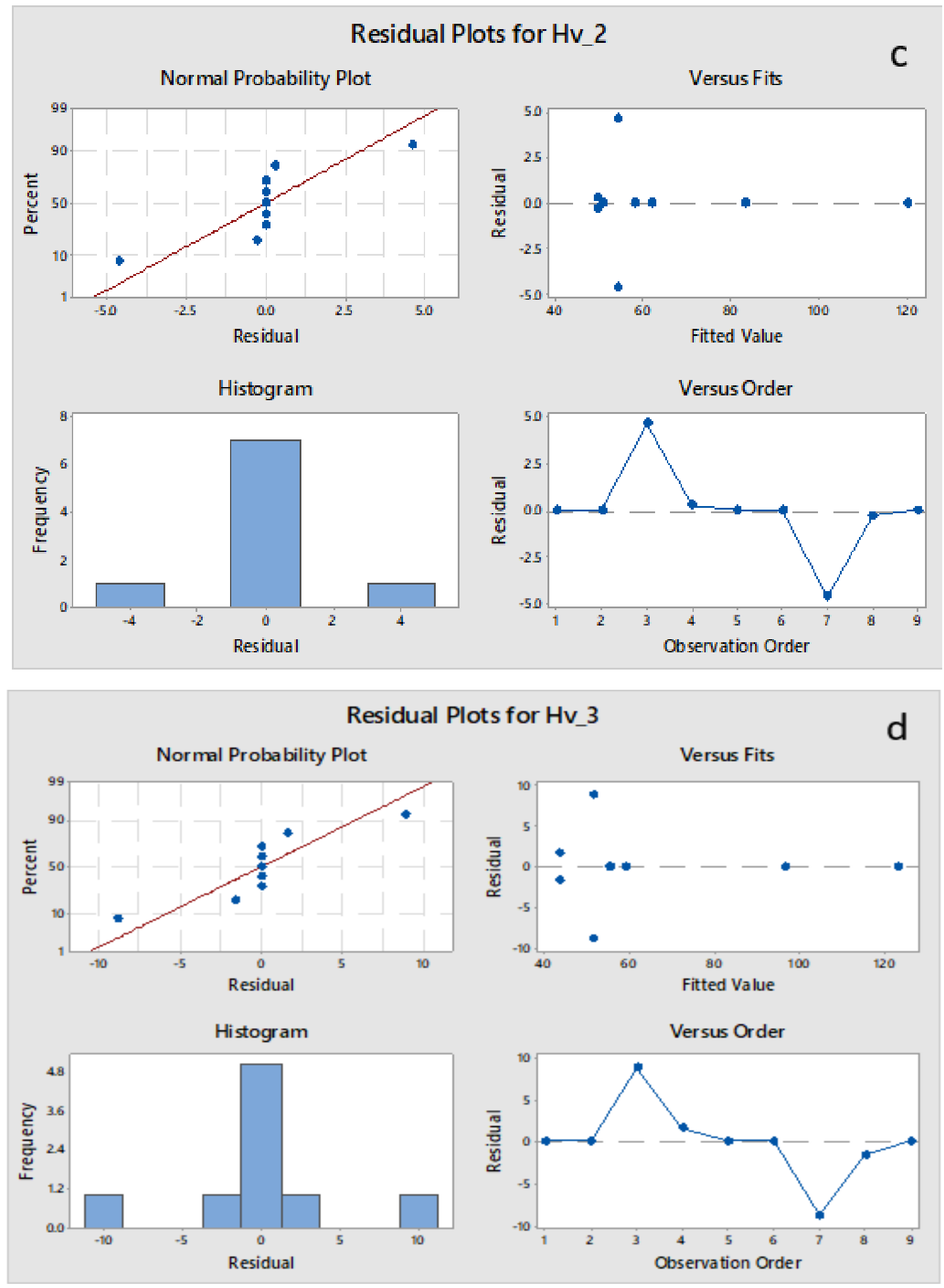

Figure 2. Correlation plot between $\delta$, density and microhardness of X7475 experimental alloy in the (a) AC, (b) O, (c) T4 and (d) T6 conditions 
The relationship plot of $\mathrm{O}$ against density and $\mathrm{H}$ in figure 3 (a) revealed the peak $\widetilde{O}$ of $3.7 \times 10^{7} \mathrm{~S} / \mathrm{m}$ observed in the AC alloy sample $\mathrm{G}$ with a $\rho$ of $2.7464 \mathrm{~g} / \mathrm{cm}^{-3}$ and a $\mathrm{H}$ of $113.06 \mathrm{Hv}$. This was due to the aging performed after quenching which allows phase transformations [4].

Obviously, the relationship was not perfectly linear and followed the result obtained by Prabhu (2017). The surface plot for $\mathrm{O}$ condition (figure $3 \mathrm{~b}$ ) shows that the peak of the plot has $\sigma$ of $3.7 \times 10^{7} \mathrm{~S} / \mathrm{m}, \rho$ of $2.752 \mathrm{~g} / \mathrm{cm}^{-3}$ and $\mathrm{H}$ of $102.60 \mathrm{Hv}$. The second sharp edge represents a

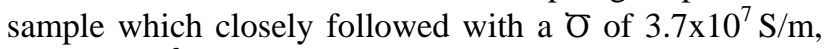
$2.743 \mathrm{~g} / \mathrm{cm}^{-3} \rho$ and $58.28 \mathrm{Hv} \mathrm{H}$ respectively.

The surface plot of T4 conditioned samples (figure 3c) has a sharp nose and evenly distributed curve surface. The obvious edge represents sample $\mathrm{C}$ with a $\rho$ of 2.7551 $\mathrm{g} / \mathrm{cm}^{-3}, 3.7 \times 10^{7} \mathrm{~S} / \mathrm{m}$ and a $\mathrm{H}$ of $58.94 \mathrm{Hv}$. All other points revealed that the optimum values following the HT process were in favour of the mechanical properties as reflected on the hip of the surface plot.

A two horns shape represents the maximum $\sigma$ of $3.7 x$ $10^{7} \mathrm{~S} / \mathrm{m}$ observed in sample $\mathrm{C}$ and for $\mathrm{G}$ respectively. The duo recorded $2.7853 \mathrm{~g} / \mathrm{cm}^{-3}$ and $2.7481 \mathrm{~g} / \mathrm{cm}^{-3}$ densities and $\mathrm{H}$ of $60.26 \mathrm{Hv}$ and $42.58 \mathrm{Hv}$ respectively. The lowest point in the surface plot is the properties displayed by an alloy (I) with $3.4 \times 10^{7} \mathrm{~S} / \mathrm{m} \mathrm{O}, 2.8513 \mathrm{~g} / \mathrm{cm}^{-3} \rho$ and 55.22 $\mathrm{Hv} \mathrm{H}$.

The linear model developed to predict the optimum relationship between the $\mathrm{H}$ and $\mathrm{\sigma}$ of the novel experimental alloys cast from recycled beverage cans that is presented below (equation i-iv). Here, $\mathrm{Hv}=\mathrm{H}$ is in the cast alloy, while $\mathrm{Hv}_{1}, \mathrm{Hv}_{2}$ and $\mathrm{Hv}_{3}$ represent $\mathrm{O}$, T4 and T6 conditions respectively.

The predicted model supported the findings that $\mathrm{H}$ and electrical $\sigma$ vary gradually along with the T4 and T6 conditions [3].

$$
\begin{array}{r}
\mathrm{Hv}=86.96+15.1 \mathrm{C} \_3.4 \times 10^{7}+3.8 \mathrm{C} \_3.5 \times 10^{7}+0.7 \mathrm{C} \_3.5 \\
\times 10^{7}+0.4 \text { C_3.5 } \times 10^{7}-11.2 \mathrm{C} \_3.5 \times 10^{7}-14.6 \mathrm{C} \_3.6 \times 10^{7}+ \\
5.7 \text { C_3.7 } \times 10^{7}
\end{array}
$$

$\mathrm{Hv}_{1}=50.37-16.5 \mathrm{C} \_3.4 \times 10^{7}+0.9 \mathrm{C} \_3.5 \times 10^{7}-12.2 \mathrm{C} \_3.5$ $\mathrm{x} 10^{7}+5.9$ C_3.5 $\times 10^{7}-8.0$ C_3.5 $\times 10^{7}-0.1$ C_3.6x10 ${ }^{7}+$ 30.1 C_3.7x $10^{7}$

$\mathrm{Hv}_{2}=68.14-10.02$ C_3.4 $\times 10^{7}-6.36$ C_3.5 $\times 10^{7}-17.50$ C_3.5 $\times 10^{7}+14.78$ C_3.5 $\times 10^{7}-18.67$ C_3.5 $\times 10^{7}+51.62$ C_3.6 $\times 10^{7}-13.85$ C_3.7 $\times 10^{7}$

$\mathrm{Hv}_{3}=69.16$ - $13.94 \mathrm{C} \_3.4 \times 10^{7}-10.12 \mathrm{C} \_3.5 \times 10^{7}-13.66$ C_3. $5 \times 10^{7}+27.30$ C_3.5 $\times 10^{7}-25.62$ C_3.5 $\times 10^{7}+53.78$ C_3.6 $\times 10^{7}-17.74$ C_3.7 $\times 10^{7}$

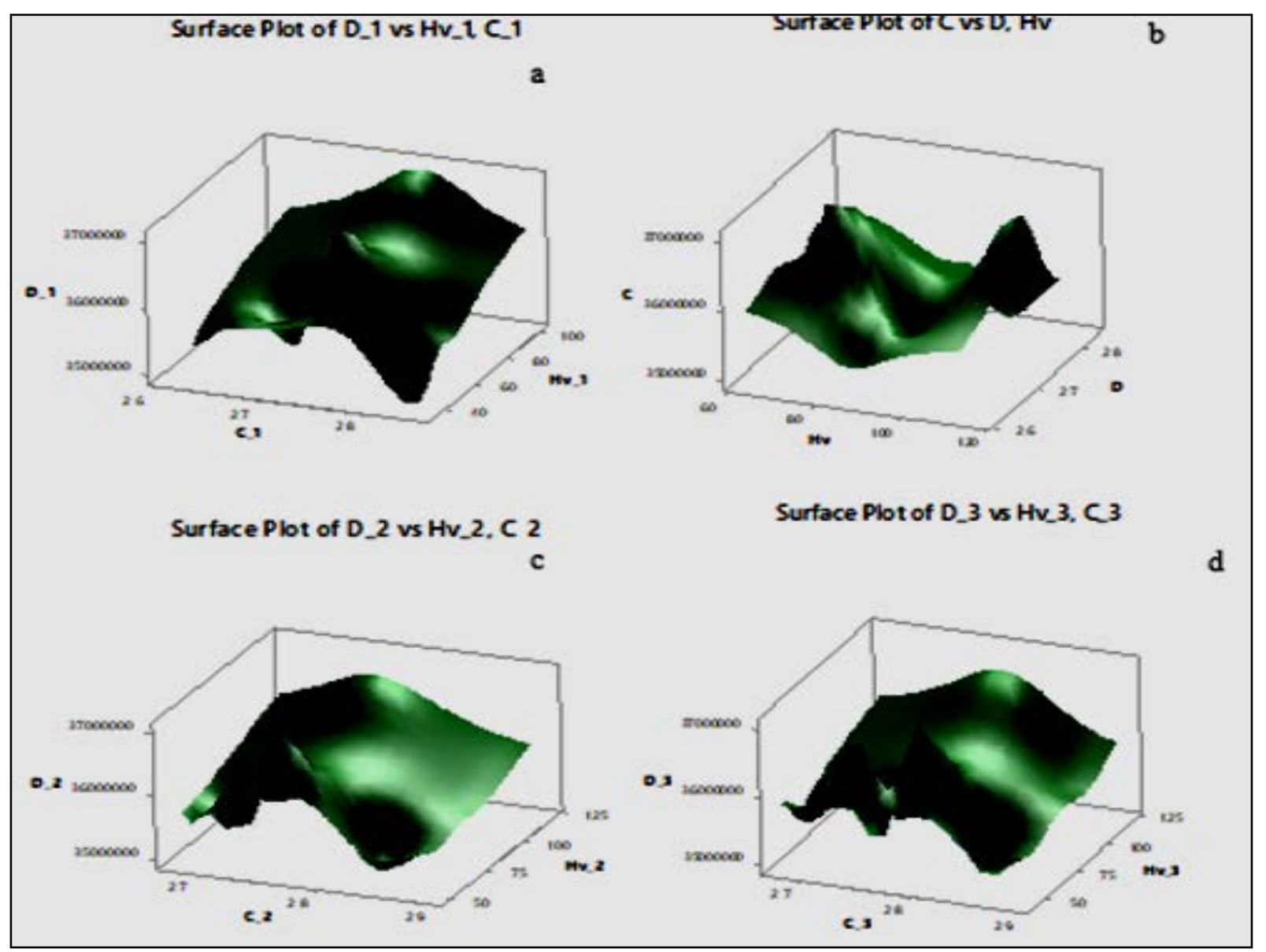

Figure 3. Response surface plot for showing the interactions between conductivity, density and microhardness of X7475 Al- alloy in the (a) AC, (b) $\mathrm{O}$, (c) T4 and (d) T6 conditions 


\section{Conclusions}

The relationship between conductivity and hardness is not perfectly inverse. The formation of hardening phases, addition of alloying constituents and impurities have effect on the $\bar{\sigma}$ and precipitates which obstruct the flow of potential within the lattice of the alloy. Density and $\sigma$ correlate with hardness. The data generated fits the model and is suffice to describe the pattern of the $\sigma$ of these experimental alloys. The paper submits further destructive tests like tensile strength and wear resistance. Optimization of mechanical properties is germane to better performance of this experimental alloy. Areas of application of this novel material may focus on the beam of automobile bumper.

\section{REFERENCES}

[1] J. Davis, “Alloying: understanding the basics,” Mater. Sci. Technol., pp. 192-203, 2001.

[2] T. R. Prabhu, "Effects of ageing time on the mechanical and conductivity properties for various round bar diameters of AA 2219 Al alloy,” Eng. Sci. Technol. an Int. J., vol. 20, no. 1, pp. 133-142, 2017.

[3] M. A. Salazar-Guapuriche, Y. Y. Zhao, A. Pitman, and A. Greene, "Correlation of Strength with Hardness and Electrical Conductivity for Aluminium Alloy 7010,” Mater. Sci. Forum, vol. 519-521, pp. 853-858, 2006.

[4] Z. Kwak, S. Rzadkosz, A. Garbacz-Klempka, M. Perek-Nowak, and W. Krok, "The properties of 7xxx series alloys formed by alloying additions,” Arch. Foundry Eng., vol. 15, no. 2, pp. 59-64, 2015.

[5] A. Kazeem, N. A. Badarulzaman, W. Fahmin, F. Bin, and W. Ali, "Effect of Isothermal Heat Treatment on Hardness of X7475 Aluminium Alloys,” vol. 2, no. 2, pp. 233-239, 2019.

[6] A. Hossain and A. S. W. Kurny, "Optimization of Artificial Ageing Time and Temperature on Evaluation of Hardness and Resistivity of Al-Si-Mg (Cu or \& Ni) Alloys,” Int. J. Chem. Mol. Nucl. Mater. Metall. Eng., vol. 8, no. 4, pp. 290-296, 2014.

[7] J. Soto, G. Aramburo, C. Gonzalez, J. Genesca, R. Herrera, and J. A. Juarez-Islas, "Distribution and prediction of solute in Al-Zn-Mg alloys,” Mater. Sci. Eng. A, vol. 408, no. 1-2, pp. 303-308, 2005.

[8] D. Feng, X. M. Zhang, S. D. Liu, and Y. L. Deng, "Non-isothermal 'retrogression and re-ageing' treatment schedule for AA7055 thick plate,” Mater. Des., vol. 60, pp. 208-217, 2014.

[9] M. M. Laboratories and M. M. Aerospace, "Relationship between microstructure, hardness and electrical conductivity of 2219 aluminium,” vol. 18, pp. 3288-3298, 1983. 